
\title{
25 Research Soure \\ What is the Role of Vitamin D in the Severity and Control of Asthma in Children and Adolescents: a Protocol for a Systematic Review
}

Joelia Maria Maria Costa Dias Ladeira ( $\sim$ joelialadeira73@gmail.com )

FCM: Universidade Estadual de Campinas Faculdade de Ciencias Medicas https://orcid.org/00000003-3450-1201

\section{Olívia Zacas}

Universidade Estadual de Campinas - Campus Cidade Universitaria Zeferino Vaz: Universidade Estadual de Campinas

Adyleia Aparecida Dalbo Contrera Toro

Universidade Estadual de Campinas Faculdade de Ciencias Medicas

Milena Baptistella Grotta

Universidade Estadual de Campinas Faculdade de Ciencias Medicas

Amanda Miranda Ferreira

Universidade Estadual de Campinas Faculdade de Ciencias Medicas

Patrícia Chaib Gomes Stegun

Universidade Estadual de Campinas Faculdade de Ciencias Medicas

\section{Protocol}

Keywords: Asthma, Vitamin D, Children, Adolescent

Posted Date: December 20th, 2021

DOI: https://doi.org/10.21203/rs.3.rs-1142825/v1

License: (a) (1) This work is licensed under a Creative Commons Attribution 4.0 International License. Read Full License 


\section{Abstract}

\section{Background:}

Vitamin D plays an important role in the immune system and consequently in the inflammatory process of asthma. It acts directly on the regulation of Th1 and Th2 cells and regulatory T lymphocytes. Evidence shows that vitamin $\mathrm{D}$ can act on dendritic cells, raising inflammatory mediators and increasing the imbalance between Th1, Th2, and Th17. Understanding the link between vitamin D and inflammatory processes in the control and severity of asthma is important for the existence of specific therapies.

Objective: We aim to synthesize the scientific evidence about the role of Vitamin D in the control and severity of asthma in pediatric patients by a systematic review.

\section{Methods:}

A systematic and comprehensive search will be performed using MEDLINE PubMed, BIREME, EBSCOhost, Scopus, Web of Science, EMBASE, Cochrane Library, and ProQuest. From the data obtained, all the articles found will be transferred to the Rayyan platform. Study selection will follow the Preferred Reporting Items for Systematic Reviews and Meta-Analyses checklist (PRISMA-2020). Additionally, if sufficient data are available, a meta-analysis will be conducted.

\section{Discussion:}

The ability of vitamin $\mathrm{D}$ to act in the immune system with a direct action on the inflammatory asthma cascade, allows for a better understanding of the disease. This will lead to better asthma management, and, consequently, to help in controlling the disease.

The conduction of a systematic review will bring better knowledge about vitamin $D$ and its role in the pathophysiology of asthma

\section{Systematic review registration:}

This protocol has been registered in the PROSPERO and the registration number is CRD42021221638.

\section{Introduction}

Asthma is the most common chronic illness in childhood. Considered a heterogeneous syndrome, it is characterized by chronic airways inflammation and history of respiratory symptoms such as wheeze, shortness of breath, chest tightness and cough that vary both over time and in intensity along with variable expiratory airflow limitation [1]. This heterogeneity is related to the phenotype of each patient, which is defined as a set of observable properties of the organism added to genetic and environmental conditions $[1,2,3]$.It is associated with clinical and biological aspects, with molecular, cellular and functional characteristics. 
Vitamin D deficiency is currently associated with asthma. The protective effects of vitamin D in asthma could be attributable to its immunomodulatory properties [4]. Its relationship with asthma is the focus of interest in recent years due to its interference in fetal lung development, regulation of the balance of Th1 and Th2 cells and maintenance of the number and functions of Treg cells [5]. Evidence shows that vit D deficiency interferes with the maturation of dendritic cells, increasing inflammatory mediators, inhibiting Th1 and Th17 and stimulating Th2 production. At normal levels, it can inhibit Th1 and Th2 responses and stimulate Treg cells to secrete IL10 and TGF- $\beta$ [6]. It can also act on Th17 lymphocytes by inhibiting the secretion of interleukin 17 , which has been associated with the presence of severe asthma [7].

Genetic evidence links several genes connected to asthma that can be regulated by vit $D$ and the polymorphism in its receptors that may be related to an increased risk of crises $[8,9]$.

Furthermore, vit D reduces hypertrophy in bronchial smooth muscle, hyperplasia of goblet cells, subepithelial deposition of collagen and fibroblast activity, which leads to a decrease in the asthma remodeling process [9].

Several articles and evaluations in this field show insufficient levels of vit $D$ are associated with exacerbation of asthma attacks in children and adolescents.

This systematic review will aim to identify, select, and appraise the role of vitamin D in the control and severity of asthma.

\section{Method}

\subsection{The registration}

This systematic review protocol was registered with the International Prospective Register of Systematic Reviews (PROSPERO) in January, 2021 (registration number CRD42021221638). We will describe the changes in the full review if necessary. The consent of this protocol report is based on the Preferred Reporting Items for Systematic Review and Meta-Analysis Protocols (PRISMA-P) 2020 statement guidelines. Furthermore, we elaborated the guiding question of this review, to ensure the systematic search of scientific literature using the PICOS (Population / Intervention / Comparison / Outcomes / Study Design).

\subsection{Inclusion criteria for study selection}

Table 1 shows the inclusion and exclusion criteria used in study screening, first by title and abstract and then by full text. Articles will be included if they are primary studies or systematic reviews of any study design. The study population must be composed of children or adolescents with asthma. Studies should investigate the role of vitamin $\mathrm{D}$ in asthma control and severity.

Table 1 - Inclusion and exclusion criteria 
Include

Types of studies: randomized trials, observational studies (including cohort and case-control studies) and also secondary studies

Population: patients between 2 and 18 years old, of all ethnicities and genders

Language: articles published in English

Outcome: higher levels of vitamin D correspond with better control and less severity of asthma
Exclude

Types of studies: case report and letter to editor

Population: adults, pregnant women, elderly, animals or infants with congenital heart defects

Language: non-English articles

Outcome: recurrent wheezing by other causes

\subsubsection{Study designs}

This review will include all types of primary study design including randomised control trials, prospective observational case-control studies and cohort studies, published in English.

\subsubsection{Type of participants}

All children or adolescents diagnosed with asthma, and with serum vitamin D levels, without race or gender restrictions.

\subsubsection{Interventions}

Interventions to be examined will include any studies of serum vitamin $\mathrm{D}$ in children and adolescents with asthma who have difficulty controlling the disease, use of high-dose corticosteroids, or had severe exacerbations during the intervention or follow-up.

\subsubsection{Outcome}

The primary outcome:

Low vitamin $\mathrm{D}$ concentrations are related to higher risks of asthma exacerbations and most frequently the use of anti-inflammatory medications as corticosteroids.

The secondary outcome:

Vitamin D and its anti-inflammatory effect through the regulation of Treg cells. Vitamin D supplementation and its ability to improve asthma control, especially in patients with severe disease.

\subsection{Data sources and search strategy}

We will search the following electronic bibliographic databases: PubMed, BVS-BIREME, EMBASE, EBSCOhost, Scopus, Web of Science, ProQuest, and the Cochrane Library and will use the following 
search strategy: (Child OR Adolescent) AND Asthma AND ("Vitamin D" OR Cholecalciferol) AND ("Inflammation Mediators" OR Lymphocytes OR Biomarkers OR Interleukins).

\subsection{Data collection and analysis}

\subsubsection{Selection of studies}

The selected literature will be managed by using Rayyan, and the screening will be a two-step process, first by title and abstract, and then by full text. A third investigator will be involved in the case of any disagreements or inconsistency left unresolved by consensus. Duplicated articles will be identified and excluded. To get qualified studies, we will then screen the full text reports and decide whether these meet the inclusion criteria and then exclude studies with incomplete information. Details of the study selection procedure are shown in Figure 1.

\subsubsection{Data extraction and management}

Data from eligible articles will be extracted independently by 2 reviewers and any disagreements will be resolved by discussion with any ongoing differences in opinion being arbitrated by a third reviewer. Data extracted will be the following: study characteristics, author names, year published, patient characteristics, data needed for quality assessment and outcomes.

\subsubsection{Assessment of risk of bias in included studies}

The risk of bias for non-randomized studies will be assessed using Joanna Briggs critical appraisal Tools (JBI) for cross section studies and the Newcastle-Ottawa scale (NOS) for case-control studies and cohort, which assesses 3 parameters of study quality: selection, comparability, and exposure assessment. It assigns a maximum score of 4 for selection, 2 for comparability, and 3 for exposure, for a maximum total score of 9 . Studies with a total NOS score of 5 or greater are considered to be of moderate to high quality, whereas those with an NOS score of less than 5 are considered low-quality studies. If we include randomized trial studies, we will assess their risks of bias with RoB 2.0 (a revised tool to assess the risks of bias in randomized trials). The quality of evidence for clinical outcomes will be assessed according to recommendations of the GRADE working group.

\section{Discussion}

Asthma is the most prevalent chronic respiratory disease worldwide [12]. If this review shows that vitamin D can help to control the disease, reducing the risk of severe asthma, it will support the hypothesis of a causal relationship between the level of that hormone and the development of asthma. Furthermore, we hope that this study can support the premise about the biological mechanism by which this might occur. This can have potentially enormous clinical implications, especially with the possibility to reduce asthma attacks, corticosteroids use, and hospitalization crises [12]. 
Careful consideration of the research to date and future evidence-based recommendations will be needed to respond to patients' concerns appropriately and precisely. Therefore, we planned this systematic review to summarize and assess the published evidence to date [13].

\section{Abbreviations}

GRADE Grading of Recommendations Assessment, Development and Evaluation

IL10 Interleukin 10

JBI Joanna Briggs Institute

NOS Newcastle-Ottawa scale

PICOS Population, Intervention, Comparison, Outcomes, Study Design.

PRISMA-P Preferred Reporting Items for Systematic Review and Meta-Analysis

PROSPERO International Prospective Register of Systematic Reviews Protocols

RoB Risks of Bias in Randomized Trials

Th1 Helper T lymphocytes 1

Th2 Helper T lymphocytes 2

Th17 Helper T lymphocytes 17

TGF- $\beta$ Transforming Growth Factor Beta

Treg T Regulatory T lymphocytes

Vit D Vitamin D

\section{Declarations}

Ethics and dissemination:

Not applicable

Consent for publication

Not applicable

Availability of data and materials 
Not applicable

\section{Competing interests}

The authors declare that they have no competing interests.

\section{Funding}

This review is not funded by any institution

\section{Acknowledgements}

Mrs. Ana Paula Oliveira. Universidade Estadual de Campinas, Campinas SP, Brazil

\section{Author contributions}

All authors contributed equally to the development of the paper. All authors approved the final version.

\section{References}

1. Global Initiative for Asthma - GINA [Internet]. Global initiative for asthma - global initiative for asthma - GINA; [citado 25 nov 2021]. Disponível em: https://ginasthma.org/.

2. Santus P, Saad M, Damiani G, Patella V, Radovanovic D. Current and future targeted therapies for severe asthma: managing treatment with biologics based on phenotypes and biomarkers.

Pharmacological Research [Internet]. Ago 2019 [citado 25 nov 2021];146:104296. Disponível em: https://doi.org/10.1016/j.phrs.2019.104296

3. Reis AP, Machado JA. Biomarcadores e imunobiológicos na asma. Brazilian Journal of Allergy and Immunology (BJAl) [Internet]. 2018 [citado 25 nov 2021];2(4). Disponível em: https://doi.org/10.5935/2318-5015.20180054

4. Hamzaoui A, Maalmi H, Berraïes A, Tanguouru E, Ammar J, Abid H, Hamzaoui A. The impact of vitamin $D$ deficiency on immune $T$ cells in asthmatic children: a case-control study. Journal of Asthma and Allergy [Internet]. Maio 2012 [citado 25 nov 2021]:11. Disponível em: https://doi.org/10.2147/jaa.s29566

5. Chary AV, Hemalatha R, Murali MV, Jayaprakash D, Kumar BD. Association of T-regulatory cells and CD23/CD21 expression with vitamin D in children with asthma. Annals of Allergy, Asthma \& Immunology [Internet]. Maio 2016 [citado 25 nov 2021];116(5):447-54. Disponível em: https://doi.org/10.1016/j.anai.2016.02.018

6. Batmaz SB, Arıkoğlu T, Tamer L, Eskandari G, Kuyucu S. Seasonal variation of asthma control, lung function tests and allergic inflammation in relation to vitamin D levels: a prospective annual study. Advances in Dermatology and Allergology [Internet]. 2018 [citado 25 nov 2021];35(1):99-105. Disponível em: https://doi.org/10.5114/ada.2017.71421 
7. Herrera G AM. Vitamina D y asma: artículo de revisión. Revista Chilena De Enfermedades Respiratorias [Internet]. Set 2013 [citado 25 nov 2021];29(3):149-54. Disponível em: https://doi.org/10.4067/s0717-73482013000300004

8. Santos HL, Silva SD, Paula ED, Pereira-Ferrari L, Mikami L, Riedi CA, Chong-Neto HJ, Rosário NA. Mutações do gene do receptor de vitamina d e níveis séricos de vitamina d em crianças com asma. Revista Paulista De Pediatria [Internet]. 26 jul 2018 [citado 25 nov 2021];36(3):269-74. Disponível em: https://doi.org/10.1590/1984-0462/;2018;36;3;00016

9. Wandalsen GF, Solé D. Vitamina d e asma: uma relação ainda por esclarecer. Revista Paulista De Pediatria [Internet]. Set 2018 [citado 25 nov 2021];36(3):250-1. Disponível em: https://doi.org/10.1590/1984-0462/;2018;36;3;00020

10. Hall SC, Agrawal DK. Vitamin D and bronchial asthma: an overview of data from the past 5 years. Clinical Therapeutics [Internet]. Maio 2017 [citado 25 nov2021];39(5):917 29.Disponível em: https://doi.org/10.1016/j.clinthera.2017.04.002

11. Wang M, Liu M, Wang C, Xiao Y, An T, Zou M, Cheng G. Association between vitamin D status and asthma control: a meta-analysis of randomized trials. Respiratory Medicine [Internet]. Abr 2019 [citado 25 nov 2021];150:85-94. Disponível em: https://doi.org/10.1016/j.rmed.2019.02.016

12. Quinn LA, Shields MD, Sinha I, Groves HE. Respiratory syncytial virus prophylaxis for prevention of recurrent childhood wheeze and asthma: a systematic review. Systematic Reviews [Internet]. 25 nov 2020 [citado 25 nov 2021];9(1). Disponível em: https://doi.org/10.1186/s13643-020-01527-y

13. Corney KB, Pasco JA, Stuart AL, West EC, Quirk SE, Azimi Manavi B, Williams LJ. Relationship between adverse childhood experiences and Alzheimer's disease: a systematic review and metaanalysis protocol. BMJ Open [Internet]. Ago 2021 [citado 25 nov 2021];11(8):e049768. Disponível em: https://doi.org/10.1136/bmjopen-2021-049768

14. Zhang W, Wang Q, Liu L, Yang W, Liu H. Effects of physical therapy on lung function in children with asthma: a systematic review and meta-analysis. Pediatric Research [Internet]. 3 abr 2020 [citado 25 nov 2021]. Disponível em: https://doi.org/10.1038/s41390-020-0874-x

15. Jung Y, Kim J, Park DA. Effectiveness of Telemonitoring Intervention in Children and Adolescents with Asthma: A Systematic Review and Meta-Analysis. Journal of Korean Academy of Nursing [Internet]. 2018 [citado 25 nov 2021];48(4):389. Disponível em: https://doi.org/10.4040/jkan.2018.48.4.389

16. Reich R, Helal L, Mantovani VM, Rabelo-Silva ER. Hemostasis after percutaneous transfemoral access. Medicine [Internet]. 24 dez 2020 [citado 25 nov 2021]; 99(52):e23731. Disponível em: https://doi.org/10.1097/md.0000000000023731

17. Faieta JM, Devos H, Vaduvathiriyan P, York MK, Erickson KI, Hirsch MA, Downer BG, van Wegen EE, Wong DC, Philippou E, Negm A, Ahmadnezhad P, Krishnan S, Kahya M, Sood P, Heyn PC. Exercise interventions for older adults with Alzheimer's disease: a systematic review and meta-analysis protocol. Systematic Reviews [Internet]. 4 jan 2021 [citado 25 nov 2021];10(1). Disponível em: https://doi.org/10.1186/s13643-020-01555-8 
18. Page MJ, McKenzie JE, Bossuyt PM, Boutron I, Hoffmann TC, Mulrow CD et al. The PRISMA 2020 statement: An updated guideline for reporting systematic reviews. Journal of Clinical Epidemiology [Internet]. Jun 2021 [citado 25 nov 2021];134:178-89. Disponível em:

https://doi.org/10.1016/j.jclinepi.2021.03.001

\section{Figures}

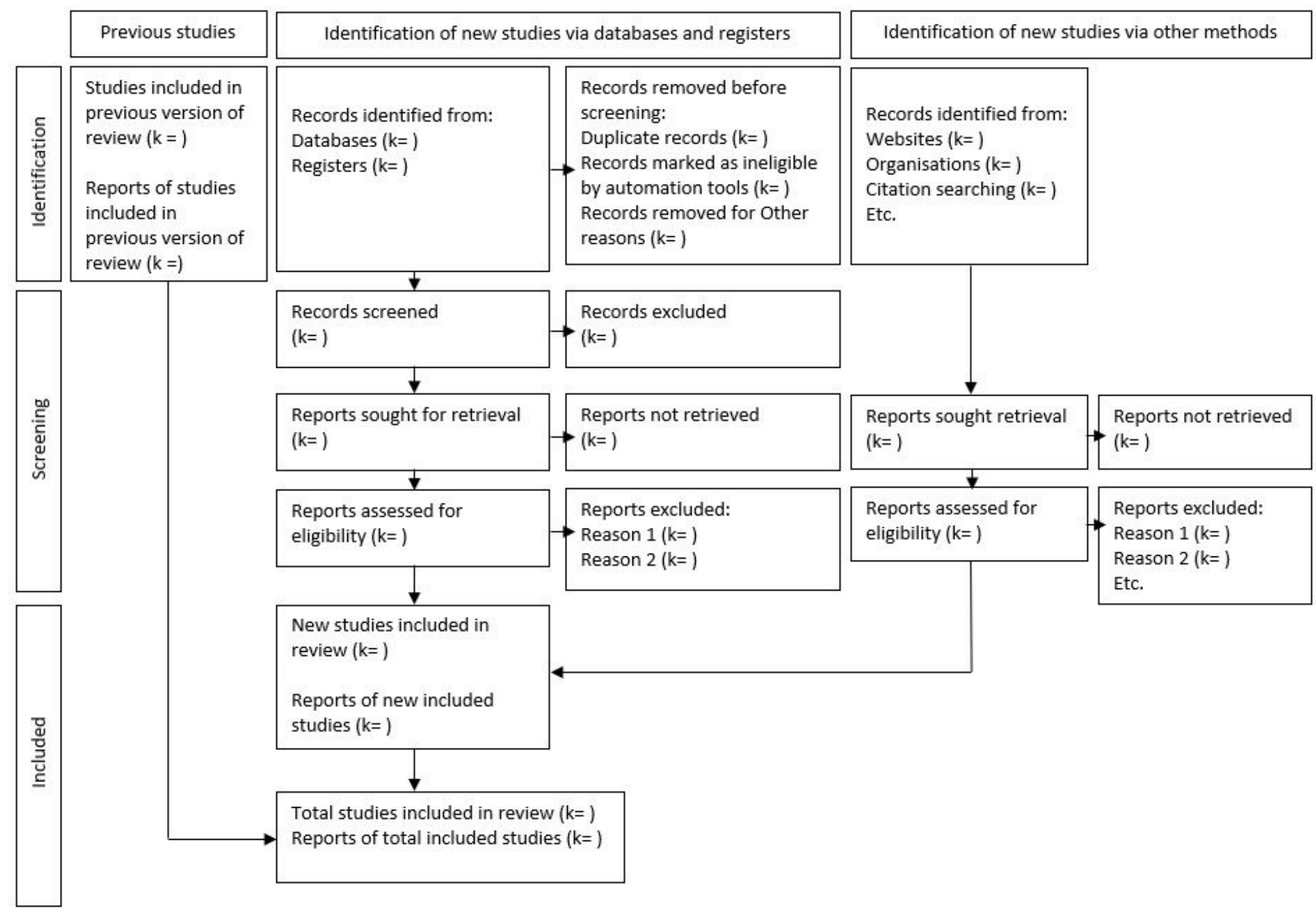

Figure 1

Information flow with the different phases of a systematic review.

\section{Supplementary Files}

This is a list of supplementary files associated with this preprint. Click to download. 